\title{
SLOPE MONITORING SYSTEM FOR NUCLEAR POWER PLANTS
}

\author{
Yonghee Lee ${ }^{1}$, Weon-Hack Choi ${ }^{2}$ \\ ${ }^{1}$ Senior Researcher, Central Research Institute, Korea Hydro \& Nuclear Power Co., Ltd., Korea \\ ${ }^{2}$ Group Leader, Central Research Institute, Korea Hydro \& Nuclear Power Co., Ltd., Korea
}

\begin{abstract}
When the great earthquake of east Japan had been occurred in 2011, embankment slope failure at the NPP site caused a station blackout, which led to loss of cooling function and ultimately resulted in release of radioactive materials to the outside environment (Massaki et al., 2014). Besides the seismic loading, rainfall has an effect on the slope stability. Generally the most important factors among the external loadings are earthquake and rainfall. But according to the increasing localized heavy rainfall in Korea, a lot of slope failures have been occurred. Subsequently, the importance of the slope safety in NPP sites drew attention from the nuclear power industry. KHNP (Korea Hydro \& Nuclear Power Co., Ltd.) regularly has been carrying out inspection on the slopes at NPP sites. Because most of the inspections had been performed by naked eye, inspectors cannot figure out small or invisible deformation. So KHNP developed K-SLOPE System (KHNP SLOPE Maintenance \& Management System) to establish much more systematic and quantitative measurement of slope behaviour by installing several kinds of monitoring devices.
\end{abstract}

\section{INTRODUCTION}

Typically, monitoring means not only simple measuring but also understanding of overall state by installing monitoring devices. Through the slope monitoring, inspectors could figure out precise slope behaviour. KINS(2011), US NRC(2007) and IAEA(2011) guidelines recommend slope monitoring during and after construction to detect occurrences that could detrimentally affect the NPP facilities. KHNP had reviewed several kinds of monitoring devices like piezometer, global positioning system, settlement monument, photogrammetry, inclinometer, tiltmeter, seismometer etc., monitoring methods and installation location. Finally selected monitoring devices were inclinometer, tiltmeter, piezometer, tension-wire, precipitation gauge and volumetric water content device. Installed slope location is behind of OO NPP reactor building in Korea and its slope height is $45 \mathrm{~m}$. Measuring by each monitoring devices is automatically performed in every 1 hour and recorded by the data logger installed at site. Measured data are transmitted to analysis server in KHNP Central Research Institute and automatically analysed by management criteria established by KHNP.

\section{SELECTION \& INSTALLTION OF SLOPE MONITORING DEVICES}

Figure 1 is slope monitoring devices installed in OO NPP site. Total 6 different types of monitoring devices had been installed as shown in Figure 1. Piezometer 1 set, tiltmeter 2 set, volumetric water content device(V.W.C) 5 set, tension wire 4 set, precipitation gauge 1 set, inclinometer 1 set were installed in or on the slope. Monitoring devices are shown in Figure 2 and a representative installation procedure for inclinometer is displayed in Figure 3. 
$24^{\text {th }}$ Conference on Structural Mechanics in Reactor Technology BEXCO, Busan, Korea - August 20-25, 2017 Division IX (include assigned division number from I to X)

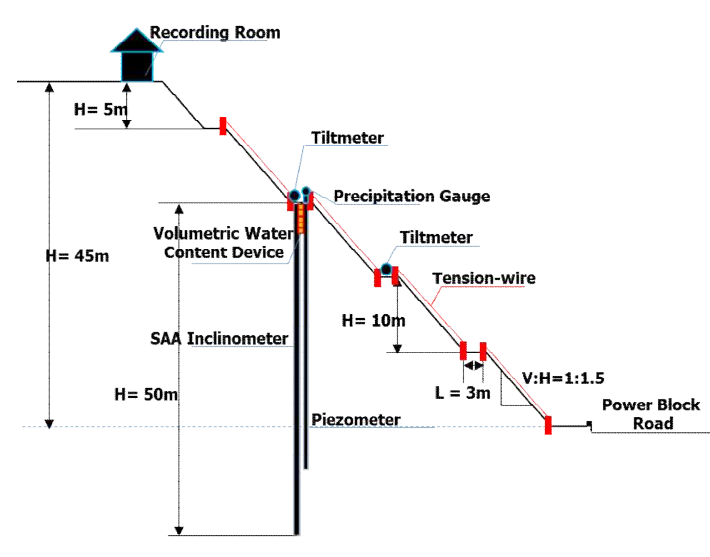

(a) Monitoring device arrangement

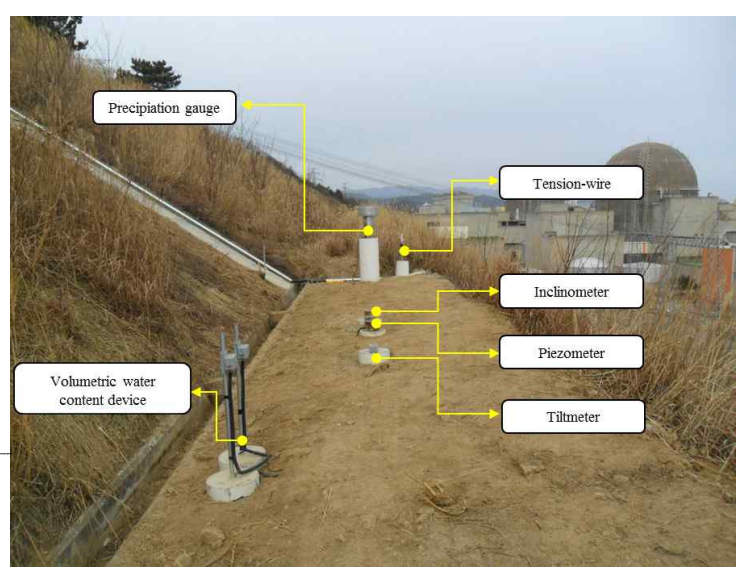

(b) Installed slope monitoring devices

Figure 1. Slope monitoring devices installed in OONPP site

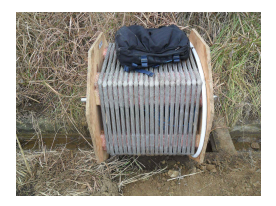

(a) Inclinometer

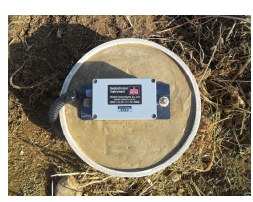

(b) Tiltmeter

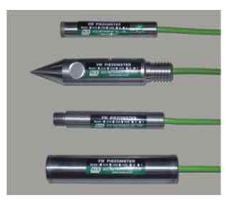

(c) Piezometer

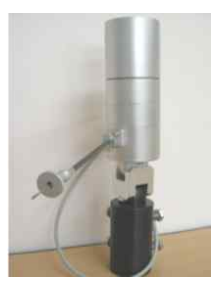

(d) Tension wire

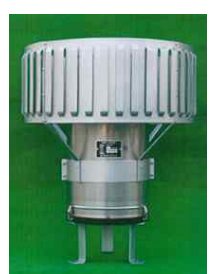

(e) Precipitation

Gauge.

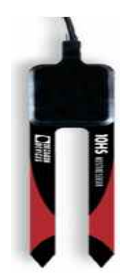

(f) V.W.C device

Figure 2. Monitoring devices installed in OO NPP site

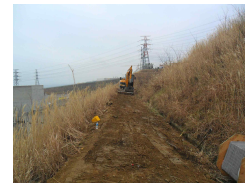

(a)Opening access road

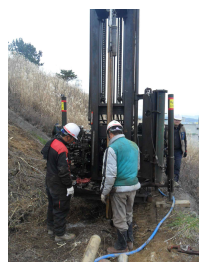

(c) Boring

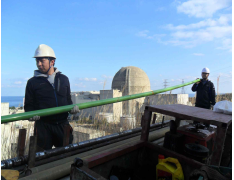

(d) Protection tube installation

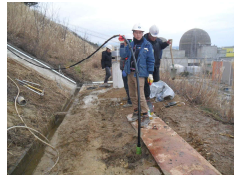

(e) Spacer Installation

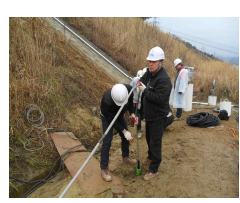

(f) Inclinometer Insertion

movement

Figure 3. A representative procedure of inclinometer installation

The purpose of each monitoring device is shown in Table 1 .

Table 1. Purpose of monitoring device installation

\begin{tabular}{|l|l|l|}
\hline \multicolumn{1}{|c|}{ Type of Device } & \multicolumn{1}{c|}{ Location } & \multicolumn{1}{c|}{ Purpose } \\
\hline Inclinometer & Bore hole & Deformation of slope \\
\hline Tiltmeter & Ground surface & Change of slope surface angle \\
\hline Piezometer & Bore hole & Monitoring of ground water table \\
\hline Tension Wire & Ground surface & Deformation of slope \\
\hline Precipitation Gauge & Ground surface & Measurement of precipitation \\
\hline Volumetric Water Content Device & Subsurface & Change of volumetric water content \\
\hline
\end{tabular}




\section{DATA TRANSMISSION \& ANALYSIS}

Measured data are temporally stored at field data logger installed in monitoring recording room in every 1 hour and automatically transmitted to analysis server installed KHNP Central Research Institute by TCP/IP communication. K-SLOPE System arrangement is shown in Figure 4. Analysis server automatically run analysis program and perform all kinds of data analysis by KHNP's management criteria in every 1 hour. And its result is displayed in user's screen (Figure 5).

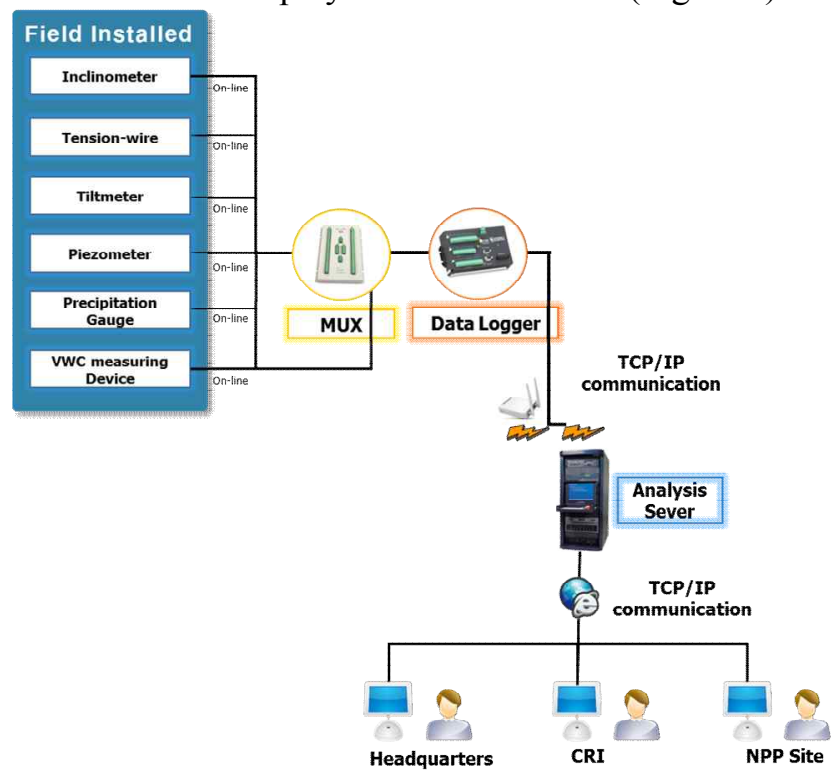

Figure 4. K-SLOPE System Arrangement

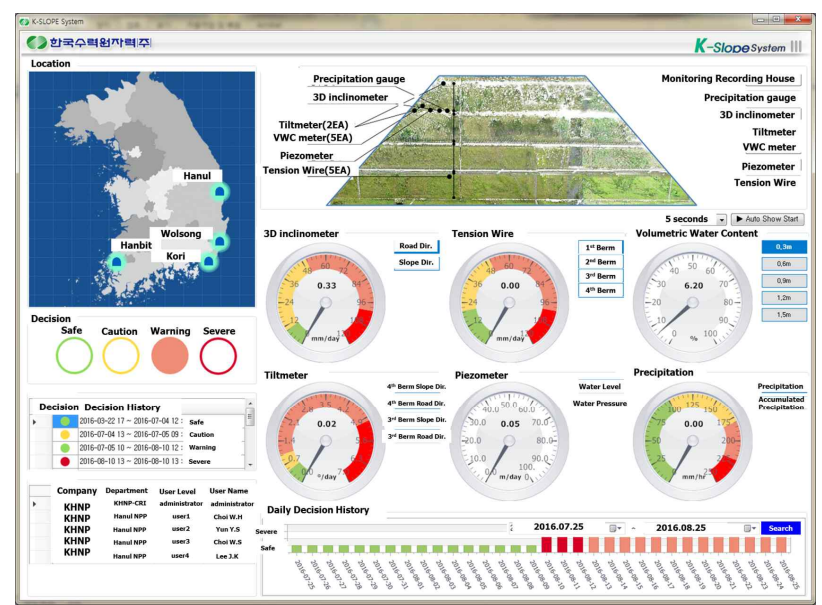

(a) Monitoring screen

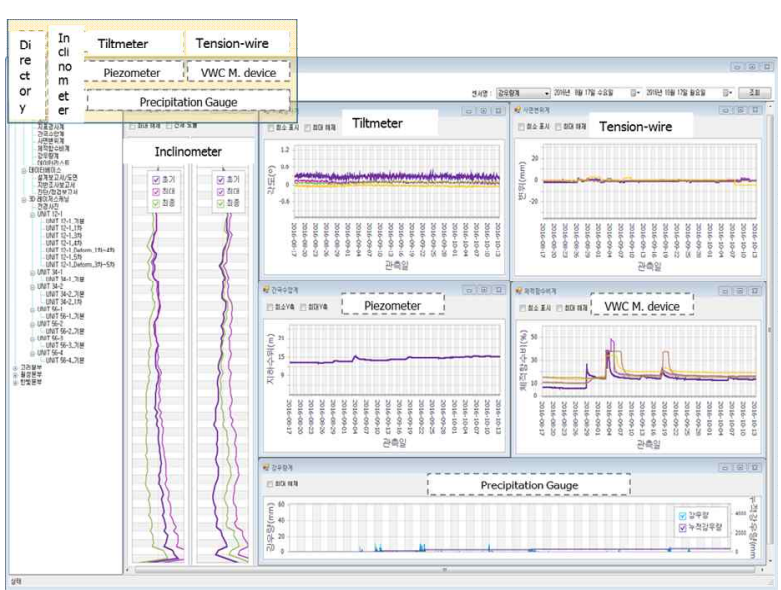

(b) Graph screen

Figure 5. K-SLOPE System

K-SLOPE System is composed of monitoring and graph screen. In the monitoring screen, monitoring location, decision for slope stability, decision history, users, monitoring device installation location in the slope, current value for each monitoring device and daily decision history are displayed. Decision represents the current state of the monitoring slope stability. It is divided into safe, cautious, warning and severe stage. Management criteria established by KHNP is shown in Table 2 and also KHNP criteria consider daily displacement, cumulative displacement, precipitation per hour and precipitation per day at the same time. Among the monitoring values most conservative value is adopted in the K-SLOPE System. 
Table 2. Management criteria for slope stability

\begin{tabular}{|c|c|c|c|c|c|c|}
\hline \multirow[b]{2}{*}{ Type of device } & \multirow[b]{2}{*}{ Unit } & \multicolumn{4}{|c|}{ Decision for slope stability } & \multirow[b]{2}{*}{ Remarks } \\
\hline & & $\begin{array}{l}\text { Safe } \\
\text { Stage }\end{array}$ & $\begin{array}{l}\text { Cautious } \\
\text { Stage }\end{array}$ & $\begin{array}{l}\text { Warning } \\
\text { Stage }\end{array}$ & $\begin{array}{l}\text { Severe } \\
\text { Stage }\end{array}$ & \\
\hline Inclinometer & $\mathrm{mm} /$ day & $\sim 10$ & $10 \sim 50$ & $50 \sim 100$ & $100 \sim$ & daily displacement \\
\hline Tiltmeter & $\%$ day & $\sim 0.5$ & $0.5 \sim 1.0$ & $1.0 \sim 5.0$ & $5.0 \sim$ & daily angle change \\
\hline \multirow{2}{*}{ Tension wire } & $\mathrm{mm} /$ day & $\sim 10$ & $10 \sim 30$ & $30 \sim 50$ & $50 \sim$ & daily displacement \\
\hline & $\mathrm{mm} / \mathrm{all}$ & $\sim 20$ & $20 \sim 50$ & $50 \sim 100$ & $100 \sim$ & cumulative displacement \\
\hline \multirow{2}{*}{ Precipitation } & $\mathrm{mm} / \mathrm{hr}$ & $\sim 30$ & $30 \sim 40$ & $40 \sim 50$ & $50 \sim$ & hourly precipitation \\
\hline & $\mathrm{mm} /$ day & $\sim 100$ & $100 \sim 180$ & $180 \sim 220$ & $220 \sim$ & daily precipitation \\
\hline $\begin{array}{l}\text { Volumetric } \\
\text { Water Content }\end{array}$ & $\% /$ day & $\sim 20$ & $20 \sim 25$ & $25 \sim 30$ & $30 \sim$ & N/A \\
\hline $\begin{array}{l}\text { Ground water } \\
\text { level }\end{array}$ & $\mathrm{m} /$ day & $\sim 0.5$ & $0.5 \sim 1.5$ & $1.5 \sim 2.0$ & $2.0 \sim$ & N/A \\
\hline
\end{tabular}

\section{CONCLUSIONS}

Up to recently slope management and maintenance in NPP sites are mainly performed by naked eye inspections. To understand slope behaviour in detail, it is generally needed to develop slope monitoring system. Slope monitoring system enables more systematic and quantitative slope maintenance and management. And also invisible deformation could be detected by monitoring devices.

KHNP constructed K-SLOPE system successfully. 6 kinds of monitoring devices were installed in OO NPP site. Every 1 hour measured data are automatically recorded and transmitted to analysis server. Automatic analysis is performed by analysis server according to the slope maintenance criteria established by KHNP and its analyses results for current slope stability are displayed in user friendly screen.

\section{REFERENCES}

IAEA(2011), "Geotechnical Aspects of Site Evaluation and Foundations for Nuclear Power Plants", Safe Guide No.NS-G-3.6 IAEA Safe Standards for Protecting People and the Environment.

KINS(2011), "Criteria and Guideline for PWR", KINS/RG-N01.09 in Korean

Masaaki Murata, Toru Iijima, Kazunari Mori, Hidetaka Nakamura, Morito Ohashi and Hiroaki Yamazaki (2014), "Guideline for Design and Risk Evaluation against the Seismic Stability of the Ground Foundation and the Slope", Japan Nuclear Energy Safety Organization, JNES-RE-2013-2037 in Japanese.

U.S. NRC(2007), “Slope Stability Revision 3”, NUREG-0800 Standard Review Plan. 